\title{
Simultaneous estimation of genotype by environment interaction accounting for discrete and continuous environmental descriptors in Irish dairy cattle
}

\author{
J. J. Windig, ${ }^{1}$ H. A. Mulder, D. I. Bohthe-Wilhelmus, and R. F. Veerkamp \\ Animal Breeding and Genomics Centre, Wageningen UR Livestock Research, 8200 AB Lelystad, the Netherlands
}

\begin{abstract}
Genotype by environment interaction can be analyzed by using a multi-trait model in which a trait measured in different environments is considered as separate traits. Alternatively, it can be analyzed by using a reaction norm model, in which the trait is considered a function of an environmental descriptor. Here, a model is developed where the 2 approaches are combined such that the effect of a continuous environmental descriptor can be analyzed in 2 or more discrete environments. The model is applied to somatic cell score (SCS) in relation to average herd milk production in 2 production environments: spring calving and year-round calving in Ireland. Heritabilities and additive genetic variances for SCS increased somewhat with increasing milk production and were higher in year-round calving. Under the combined model, the genetic correlation between spring and year-round calving was estimated at 0.82 to 0.84 , clearly lower than obtained in a bivariate analysis ignoring effects of herd milk production. Thus, when estimating the genetic correlation between environments, effects of one environmental descriptor may be obscured by another, but can be disentangled in an analysis combining the reaction norm and the multitrait approach. Such models will be especially useful for analyzing questions such as whether the effect of increasing production or temperature is more severe in different production systems or geographic regions.
\end{abstract}

Key words: dairy cattle, reaction norms, somatic cell count, spring calving

\section{INTRODUCTION}

Animals vary in production, fertility, health, and other important traits across environments at both the phenotypic (Windig et al., 2005) and the genetic level (Calus et al., 2005). Genotype by environment interaction $(\mathbf{G} \times \mathbf{E})$ may lead to heterogeneity of variance across environments or even reranking of sires.

Received August 16, 2010.

Accepted February 22, 2011.

${ }^{1}$ Corresponding author: jack.windig@wur.nl
Genetic correlations between traits can also vary and, consequently, selection in one environment may have different consequences in another environment (Windig et al., 2006). If considerable $\mathrm{G} \times \mathrm{E}$ is present, separate breeding programs for different environments can be advisable (Mulder et al., 2006).

The variation in environment that animals can experience has many different origins. Broadly speaking, 2 classes of environmental descriptors exist: those that describe the environment on a continuous scale (e.g., average herd milk production) and those that describe the environment on a discrete scale (e.g., production systems). For continuous environmental descriptors, $\mathrm{G} \times \mathrm{E}$ is generally analyzed with a reaction norm approach, whereas for discrete environmental descriptors, it is analyzed with a multi-trait approach.

Commonly, herd environment is classified according to average production of herds (e.g., Roxstrom et al., 2001; Kolmodin et al., 2002). In this way, many different aspects of the environment, such as feed, climate, production system, milking intensity and management, are summarized into one environmental descriptor. Other aspects of the herd environment are also classified on a continuous scale, as herd averages; for example, average fertility or fat percentage (Calus and Veerkamp, 2003), principal components (Windig et al., 2006), or single variables such as farm size (Tsuruta et al., 2009) and mean temperature (Ravagnolo and Misztal, 2002; Aguilar et al., 2009).

Interest in $\mathrm{G} \times \mathrm{E}$ interaction often arises from a specific question comparing two, or a few, different situations and, in these cases, a discrete scale is often used. Examples are production systems, such as regular versus organic (Nauta et al., 2006), grazing versus confined (Kearney et al., 2004), or high yield versus low yield (Castillo-Juarez et al., 2002), and geographic regions (Konig et al., 2005; Hammami et al., 2009). The general approach to analyzing $\mathrm{G} \times \mathrm{E}$ interaction in such discrete environments is to consider the trait under analysis in each environment as a separate trait (Falconer, 1952). These traits then have their own genetic and residual variance with a covariance between them. A genetic correlation lower than unity between 2 environments indicates reranking of genotypes across 
environments. This is generally called the multi-trait approach. Frequently, continuous environmental descriptors are divided into 2 or more groups to apply a multi-trait approach (Raffrenato et al., 2003).

Genotype by environment interaction for continuous environmental descriptors can also be analyzed with a reaction norm approach. A reaction norm can be seen as a function that describes the performance of a genotype along an environmental gradient. Heritabilities and additive genetic variances can be estimated for the parameters that describe the function; genetic correlations between the parameters may also be estimated. For example, in case of a linear function the heritability of the slope and intercept and the genetic correlation between them is estimated. Results of the reaction norm approach can be converted into a multi-trait approach by calculating the (co)variance matrix for a set of specific points along the environmental gradient (Van Tienderen and Koelewijn, 1994).

The use of either a multi-trait or a reaction norm approach should be guided by the environmental gradient analyzed; that is, continuous or discrete. When the interest is in the effect of an environmental descriptor that may take any value between a minimum and a maximum (e.g., average milk production), the reaction norm approach is the method of choice. On the other hand, when the interest is in 2 clearly separate environments; for example, biological and regular production systems, the multi-trait approach is the logical option. However, both situations may occur simultaneously. For example, $\mathrm{G} \times \mathrm{E}$ in Australian dairy cattle has been analyzed for geographic region as well as average herd production and farm size (Haile-Mariam et al., 2008). Furthermore, the interest may be in both discrete and continuous environmental descriptors at the same time; for example, whether the effect of production intensity on genotypes is different in 2 production environments. In this case, a combined approach rather than separate analyses would be needed.

In this paper, the combination of a multi-trait model and a reaction norm model is explored. The main aim was to see whether this combined model resulted in different insights compared with separate analyses. The statistical tools will be described and then applied to SCS in an Irish cattle data set with 2 production systems and herd average milk yield as a continuous environmental descriptor

\section{MATERIALS AND METHODS}

\section{Statistical Models}

The traditional model in animal breeding for estimation of variance components and breeding values is an animal, sire or sire-maternal grandsire model, where the systematic environmental effects are incorporated as fixed effects and the genetic effects are random. For a sire model, this is represented as follows:

$$
y_{i j k}=\mu+\text { fixed }_{k}+s_{i}+r_{i j k},
$$

where $y_{i j k}$ is the value for the trait of daughter $j$ of sire $i$ with fixed effect(s) $k$; fixed $_{k}$ is the fixed effects (generally a herd-year-season effect but may incorporate other effects such as calving age or production system); $s_{i}$ is the random effect of sire $i\left[N\left(0, \mathbf{A} \sigma_{s}^{2}\right)\right]$, with $\mathbf{A}$ being the numerator relationship matrix; and $r_{i j k}$ is the random residual effect $\left[N\left(0, \sigma_{r}^{2}\right)\right]$. The term residual effect, rather than environmental effect, is used to avoid confusion with systematic environmental effects.

In case of a multi-trait environmental analysis, model [1] becomes

$$
y_{i j k l}=\mu+\text { fixed }_{k}+s_{i l}+r_{i j k},
$$

where $y_{i j k l}$ is the value for the trait in environment $l$ of daughter $j$ of sire $i$, and $s_{i l}$ is the random effect of sire $i$ in environment $l$; other effects are as in model [1]. Generally, daughters have traits recorded in only 1 environment. In this case, additive genetic covariance between the trait in 2 environments is estimated together with the additive genetic variance components within environments (Table 1), while the residual covariance between the 2 environments is set to zero.

A linear reaction norm model is given by

$$
y_{i j k}=\mu+\text { fixed }_{k}+s_{a, i}+s_{b, i} X_{i j}+r_{i j k},
$$

where $s_{a, i}$ is the random intercept of the reaction norm of sire $i, s_{b, i}$ is the random linear regression coefficient (slope) of sire $i$ on $X_{i j}$, and $X_{i j}$ is the continuous environment of daughter $j$ of sire $i$; other effects are as in model [1]. Model [3] can be extended in case of nonlinear functions with higher order coefficients of polynomials. With this model, variance components are estimated for the slope, the regression, and the covariance between the 2 in case of a linear reaction norm (Table 1). The (co)variance matrix of the reaction norm model $\left(\mathrm{V}_{\mathrm{RN}}\right)$ can be converted to a (co)variance matrix of a multitrait model $\left(\mathrm{V}_{\mathrm{MT}}\right)$, where (co)variance components are estimated for specific values along the environmental gradient using

$$
V_{M T}=M_{\Phi} V_{R N} M_{\Phi}^{\prime} \text { with } M_{\Phi}=\left[\begin{array}{cc}
\Phi_{\mathrm{int}, x 1} & \Phi_{\mathrm{sl}, x 1} \\
\Phi_{\mathrm{int}, x 2} & \Phi_{\mathrm{sl}, x 2} \\
\vdots & \vdots \\
\Phi_{\mathrm{int}, x n} & \Phi_{\mathrm{sl}, x n}
\end{array}\right],
$$


Table 1. Models of increasing complexity used to estimate genotype by environment interaction; 2 discrete environments are designated as E1, $E 2$, and environments on a continuous scale are designated as $1,2, \ldots, n$ (where sl $=$ slope, int $=$ intercept)

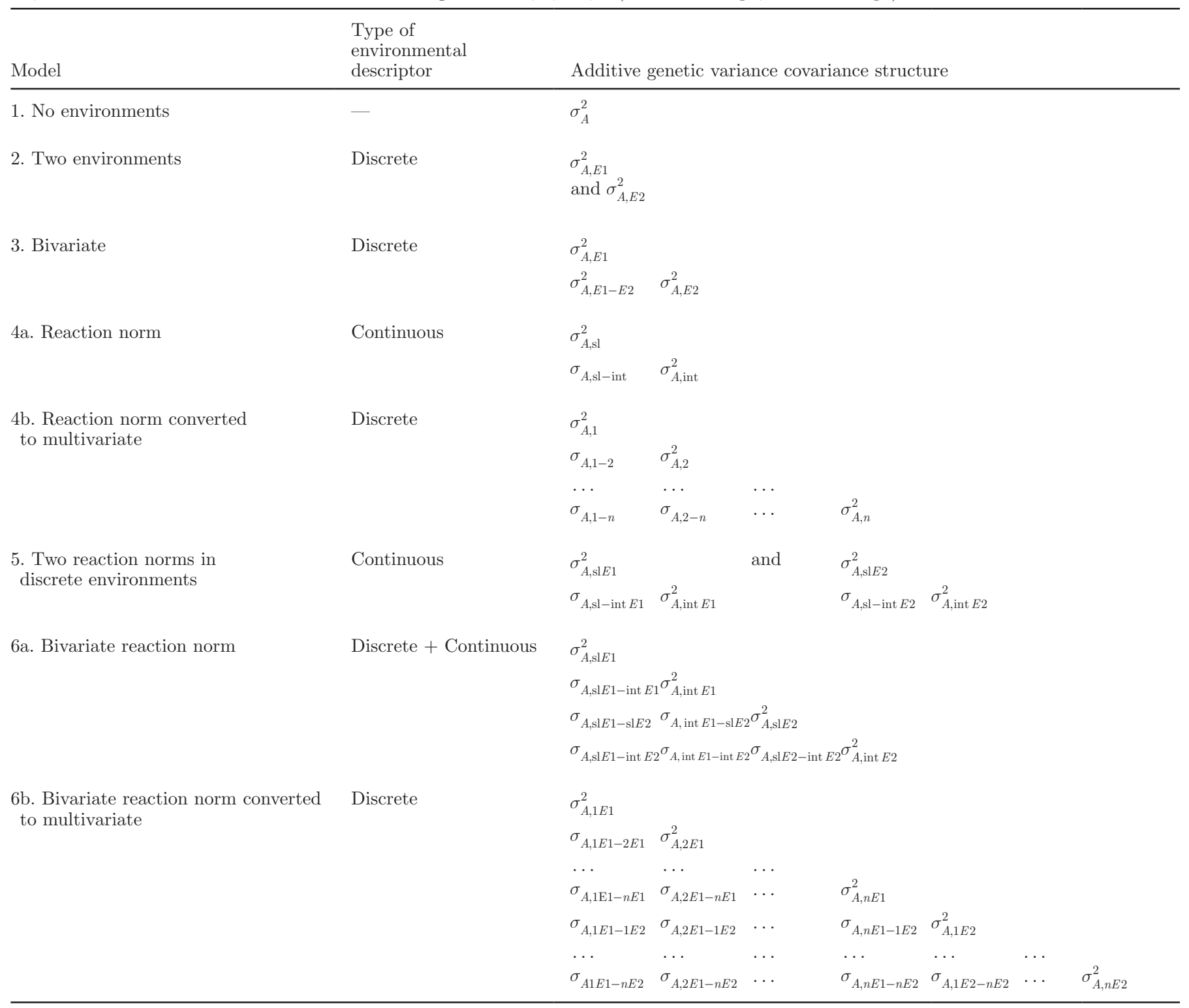

where $x 1, x 2 \ldots x n$ are $n$ points along the environmental gradient of the $x$ variable and $\Phi_{\mathrm{int}, x \#}$ and $\Phi_{\mathrm{sl}, x \#}$ are the design values for the function used in the reaction norm model for environment $x \#$.

The combination of a reaction norm model and a multi-trait model is given by

$$
y_{i j k l}=\mu+\text { fixed }_{k}+s_{a, i l}+s_{b, i l} X_{i j l}+r_{i j k},
$$

where $s_{a, i l}$ is the random intercept of the reaction norm in environment $l$ of sire $i, s_{b, i l}$ is the random linear regression coefficient (slope) in environment $l$ of sire $i$ on $X_{i j l}$, and $X_{i j l}$ is the environment defined on a continuous scale of daughter $j$ of sire $i$ in environment $l$, environ- ment $l$ being defined on a discrete scale; other effects are as in model [1]. For this combination of a multitrait and reaction norm model, the variance covariance matrix contains variances for intercept and slope and their covariance within each environment, as well as covariances between intercepts and slopes within and between the different environments (Table 1 ).

The (co)variance matrix of the combination of a multi-trait and reaction norm model can be converted to a (co)variance matrix of a multi-trait model $\left(\mathrm{V}_{\mathrm{MT}}\right)$. Variance components are estimated for specific values along the environmental gradient in each of the discrete environments, with parameters as defined in model [4]: 


$$
\begin{aligned}
V_{M T} & =M V_{R N} M^{\prime}, \text { with } \\
M & =\left[\begin{array}{cc}
M_{\Phi} & 0 \\
0 & M_{\Phi}
\end{array}\right] \text { and } M_{\Phi}=\left[\begin{array}{cc}
\Phi_{\mathrm{int}, x 1} & \Phi_{\mathrm{sl}, x 1} \\
\Phi_{\mathrm{int}, x 2} & \Phi_{\mathrm{sl}, x 2} \\
\vdots & \vdots \\
\Phi_{\mathrm{int}, x n} & \Phi_{\mathrm{sl}, x n}
\end{array}\right] .
\end{aligned}
$$

The models and their additive genetic variance components estimated with each model are summarized in Table 1.

\section{Data Set}

The models described above were applied to a data set of Irish cattle. The data set was compiled from the 305-d lactation records of all cows born between 2001 and 2005 monitored by the Irish Cattle Breeding Federation. Irish herds can be divided into spring-calving and year-round calving systems. In this study, herds were categorized as spring calving if more than $95 \%$ of calving took place from January to June or from December to May (Evans et al., 2006). The 2 systems differ not only in time of calving but also in feed, amount of grazing, and herd size (Table 2).

Only first-parity records were analyzed in this study. Animals with less than $87.5 \%$ Holstein breed fraction were excluded. Animals with lactation length $>500 \mathrm{~d}$, calving age $<20 \mathrm{mo}$ or $>36 \mathrm{mo}$, and lactation milk yield $<1,000 \mathrm{~kg}$ were also excluded, as were animals with unknown sire, dam, or maternal grandsire. Finally, bulls and their offspring with fewer than 5 daughters in each of the production systems were excluded. The final data set consisted of 60,933 records, of which 24,555 were in 1,632 spring-calving herds and 36,378 were in 1,173 year-round calving herds. Of the 289 bulls with more than 20 daughters in year-round calving herds, 175 had more than 20 daughters in spring-calving herds as well. Only 13 bulls with more than 20 daughters in spring-calving herds had fewer than 20 daughters in year-round calving herds.

\section{Data Analyses}

The trait analyzed was SCS as an indicator of mastitis infection. Lactation-average SCC was transformed to SCS as follows: $1,000+100 \times\left[\log _{2}(\mathrm{SCC} / 1,000,000)\right]$ (de Haas et al., 2008). Average herd milk yield was used as a continuous variable for classifying the environment and production system as a discrete variable. Average herd milk yield was calculated by taking the average of all Holstein cows of all parities in the herd in the years 2001 to 2006. All analyses were done with REML using the software package ASREML (Gilmour et al., 2006).

Analyses were performed using a sire-maternal grandsire model:

$$
y=\mu+h y s+b r+s_{\text {sire }}+1 / 2 s_{\text {mgs }}+r,
$$

with hys and $b r$ being the herd-year-season of calving and the Holstein breed fraction fixed effects, respectively. The random sire effects were sire $\left(s_{\text {sire }}\right)$ and maternal grandsire $\left(s_{m g s}\right)$. The factor $1 / 2$ was included because the incidence matrix of MGS effects was laid over the matrix of sire effects; that is, if a bull had entries in the data as both sire and MGS, his breeding value as MGS was equal to half the breeding value as a sire. Sire effects were linked using the relationship matrix of the sires and were assumed to be normally distributed with $\operatorname{Var}\left(s_{\text {sire }}\right)=\operatorname{Var}\left(s_{m g s}\right)=\sigma_{s}^{2}$. Because cows had a single observation in only one environment, residual effects could not be modeled as reaction norms. Therefore, residual variances in models with reaction norms were estimated separately for 5 equally sized groups based on increasing average herd milk production (e.g., each group contained $20 \%$ percentiles). Five groups were chosen so that each group contained a minimum of 10,000 records to avoid residual variances with large standard errors. To calculate the heritabilities, 4 times the sire variance was divided by the residual variance plus 1.25 times the sire variance. The latter term is because both sire effects ( 1 times the sire variance) and maternal grand sire effects ( 0.25 times the sire variance) were included in the model.

First, an analysis ignoring the influence of production system and herd average milk yield was performed (similar to model [1], first entry in Table 1). Next, the analysis was repeated for each production system separately (Table 1, second entry), giving separate estimates for spring calving and year-round calving. For

Table 2. Characteristics of the 2 production environments in the first-lactation cow data set analyzed

\begin{tabular}{lcc}
\hline Characteristic & $\begin{array}{c}\text { Spring } \\
\text { calving }\end{array}$ & $\begin{array}{c}\text { Year-round } \\
\text { calving }\end{array}$ \\
\hline Calving January-May (\%) & 96.7 & 56.5 \\
Herds (n) & 1,632 & 1,173 \\
Average heifers per herd (n) & 15 & 31 \\
Average daughters per sire (n) & 31.2 & 46.5 \\
Average 305-d milk production (kg) & 5,702 & 6,778 \\
Average SCS & 649 & 657 \\
\hline
\end{tabular}


the third analysis, SCS in spring calving was treated as a different trait from SCS in year-round calving (e.g., model [2]). In this way, a genetic covariance and a genetic correlation between SCS in the 2 environments was estimated (Table 1, third entry).

The analyses involving reaction norms assumed linear reaction norms, following results from Calus et al. (2005). First, a single reaction norm with average herd milk production as environmental descriptor was performed, ignoring the effect of production system (model [3]; Table 1, fourth entry). Next, the reaction norm analysis was repeated for each production system separately, giving separate estimates for spring calving and year round calving (Table 1, fifth entry). Finally, model [5], combining the reaction norm and multi-trait approach, was applied for each production system and average herd milk production simultaneously (Table 1 , sixth entry).

Statistical significance of differences between parameters estimated in the reaction norm analyses could not be determined exactly. Additive variance components were estimated for slopes and intercepts, whereas residual variances were estimated for different milk production environments. Therefore, approximate standard errors were estimated using the procedure as outlined by Fischer et al. (2004). In this way, standard errors may be assigned to all estimates along the environmental gradient and used as an indication of the statistical significance of the difference between 2 estimates.

Analyses involving reaction norms in spring calving tended not to converge. In case of nonconvergence after 100 iterations, parameters that had remained constant in at least the last 10 iterations (but generally over more than 25 iterations) were fixed and the analysis was restarted. In case of nonconvergence after a further 400 iterations, parameters that alternated between 2 values in consecutive iterations ("ping-ponged") were fixed to the mean of the 2 values, after which all analyses converged. Standard errors of genetic parameters could be approximated for all analyses except in the last 2 cases.

\section{RESULTS}

\section{Averages and Phenotypic Variation}

Average 305-d milk production was lower in springcalving herds $(5,781 \mathrm{~kg}$, ranging from 2,584 to 9,673 $\mathrm{kg}$ ) than in year-round calving herds $(6,921 \mathrm{~kg}$ ranging from 3,201 to $11,055 \mathrm{~kg}$ ). Somatic cell score was similar in the 2 production systems (average of 657 in yearround calving vs. 649 in spring calving), whereas the percentage of cows with $\mathrm{SCC}>150,000$ cells $/ \mathrm{mL}$ was slightly higher in spring-calving herds $(22.8 \%)$ than in year-round calving herds (20.5\%).

\section{Additive and Residual Variance and Heritabilities}

The estimated heritability for SCS was 0.060 when differences in environments were ignored. When the heritability was estimated for the 2 production systems separately, it decreased to 0.052 for spring calving and slightly increased to 0.062 for year-round calving (Table 3 ). Additive genetic variance was somewhat lower in spring calving, whereas residual variance was clearly higher in spring calving compared with year-round calving. When a bivariate model was applied, the difference in additive genetic variance between the 2 environments disappeared, while the difference in residual variance remained almost the same. Consequently, the heritability was only slightly higher for year-round calving (0.063 vs. 0.059 ).

Under the reaction norm model, a clear trend was observed in the genetic parameters when the difference in production systems was ignored. Heritability increased from 0.052 for low milk production herds to 0.069 for high milk production herds (Table 4). This trend was caused by both an increase in additive genetic variances and a decrease in residual variances. This is consistent with results from the discrete environment analysis, where heritabilities and additive genetic variances were lower and residual variances higher in the lower producing spring-calving environment.

When the reaction norm model was applied separately in the spring calving and year-round calving data sets, both showed an increase in additive genetic variances and heritabilities with increasing average herd production (Table 4). Additive genetic variances were lower for spring calving compared with year-round calving, but also compared with the multi-trait model. In the separate reaction norms, residual variances decreased in an irregular way across average herd production, both in spring calving and in year-round calving, with the residual variances in spring calving being higher than in year-round calving.

Residual variances remained almost the same under the bivariate reaction norm model as under the 2 univariate reaction norm models (Table 5 ). Additive genetic variance was increased compared with the univariate analysis, both for spring calving and year-round calving. The trend of increasing additive genetic variances with increasing production was similar in all reaction norm analyses (Figure 1). Estimated variances were similar for the highest herd milk production classes. For the lowest milk production classes, the estimated additive genetic variances varied more. The difference 
Table 3. Estimates for genetic additive variance $\left(\sigma_{A}^{2}\right)$, residual variance $\left(\sigma_{R}^{2}\right)$, heritability $\left(h^{2}\right)$, covariance, and genetic correlation $\left(\mathrm{r}_{\mathrm{A}}\right)$, with standard errors in parentheses, for models with discrete environments (year-round calving and spring calving)

\begin{tabular}{|c|c|c|c|c|c|c|}
\hline No environments & - & $590(75)$ & $9,584(59)$ & $0.060(0.008)$ & \multirow{4}{*}{$552(85)$} & \multirow{4}{*}{$0.91(0.06)$} \\
\hline Two environments & Spring calving & $528(119)$ & $10,026(97)$ & $0.052(0.011)$ & & \\
\hline \multirow[t]{2}{*}{ Bivariate } & Spring calving & $606(117)$ & $10,027(98)$ & $0.059(0.011)$ & & \\
\hline & Year-round calving & $607(82)$ & $9,283(72)$ & $0.064(0.008)$ & & \\
\hline
\end{tabular}

between the univariate and bivariate reaction norm was largest for spring calving (Figure 1). Heritabilities were higher for year-round calving (0.059 to 0.070) than for spring calving (0.054 to 0.064).

\section{Genetic Correlations}

The genetic correlation between spring calving and year-round calving was estimated as 0.91 when average herd milk production was ignored (Table 3 ). Genetic correlations between milk production environments were 1 or just less than 1 (ranging from 0.98 to 1.0), both for the reaction norm model ignoring spring or year-round calving and for the univariate reaction norms in spring calving and year-round calving (Table 6 ). Genetic correlations within spring calving and yearround calving remained almost the same in the bivariate reaction norm model as in the univariate reaction norms. Genetic correlations between spring and yearround calving varied from 0.82 to 0.84 for the different production levels, which was clearly lower than in the bivariate estimate without reaction norms (Table 7).

\section{Breeding Values}

Breeding values for the 12 bulls with most daughters in the data set ranged from -15.4 to +13.2 for different bulls in different environments (Table 8). Under the bivariate reaction norm model, average herd milk production had little influence on breeding values in yearround calving (largest difference between upper and lower $20 \%$ percentile was 0.4 ). For some bulls, however, the difference was larger in spring calving (up to 1.6). Generally, ranking of the bulls stayed the same under different models and in different environments; for example, bull 1 had always the lowest breeding value and bull 12 the highest. However, some reranking did occur; for example, bull 6 under the univariate model ranked seventh under the bivariate model in spring calving, ranked eighth under the bivariate reaction norm model

Table 4. Estimates for genetic additive variance $\left(\sigma_{A}^{2}\right)$, residual variance $\left(\sigma_{R}^{2}\right)$, and heritability $\left(h^{2}\right)$ for reaction norm models; continuous environments were defined by average herd milk production level

\begin{tabular}{|c|c|c|c|c|}
\hline Model & $\begin{array}{c}\text { Average herd } \\
\text { milk production } \\
(\mathrm{kg})\end{array}$ & $\sigma_{A}^{2}$ & $\sigma_{R}^{2}$ & $h^{2}$ \\
\hline Overall reaction norm ${ }^{1}$ & $\begin{array}{l}5,086 \\
5,868 \\
6,427 \\
7,006 \\
7,922\end{array}$ & $\begin{array}{l}533 \\
562 \\
579 \\
605 \\
641\end{array}$ & $\begin{array}{r}10,178 \\
9,736 \\
9,615 \\
9,320 \\
9,095\end{array}$ & $\begin{array}{l}0.052 \\
0.057 \\
0.059 \\
0.064 \\
0.069\end{array}$ \\
\hline Reaction norm in year-round calving ${ }^{2}$ & $\begin{array}{l}5,664 \\
6,436 \\
6,921 \\
7,355 \\
8,223\end{array}$ & $\begin{array}{l}544 \\
568 \\
585 \\
603 \\
639\end{array}$ & $\begin{array}{l}9,581 \\
9,562 \\
9,042 \\
9,252 \\
8,980\end{array}$ & $\begin{array}{l}0.056 \\
0.058 \\
0.063 \\
0.064 \\
0.070\end{array}$ \\
\hline
\end{tabular}

${ }^{1} \mathrm{SE}$ not estimated due to fixation of parameters.

${ }^{2}$ Average SE for $\sigma_{A}^{2} 91, \sigma_{R}^{2} 152$, and $h^{2} 0.01 \%$. 
Table 5. Genetic parameters estimated for bivariate reaction norm model

\begin{tabular}{|c|c|c|c|c|}
\hline \multirow[b]{2}{*}{ Environment } & \multirow{2}{*}{$\begin{array}{l}\text { Average herd } \\
\text { milk production } \\
(\mathrm{kg})\end{array}$} & \multicolumn{3}{|c|}{ Parameter $^{1}$} \\
\hline & & $\sigma_{A}^{2}$ & $\sigma_{R}^{2}$ & $h^{2}$ \\
\hline \multirow[t]{5}{*}{ Spring calving } & 4,767 & 567 & 10,277 & 0.054 \\
\hline & 5,358 & 585 & 9,927 & 0.058 \\
\hline & 5,757 & 597 & 9,887 & 0.059 \\
\hline & 6,165 & 611 & 10,192 & 0.059 \\
\hline & 6,859 & 646 & 9,844 & 0.064 \\
\hline \multirow[t]{5}{*}{ Year-round calving } & 5,664 & 579 & 9,583 & 0.059 \\
\hline & 6,436 & 594 & 9,564 & 0.061 \\
\hline & 6,921 & 606 & 8,932 & 0.066 \\
\hline & 7,355 & 619 & 9,349 & 0.065 \\
\hline & 8,223 & 646 & 8,978 & 0.070 \\
\hline
\end{tabular}

${ }^{1}$ Genetic additive variance $\left(\sigma_{A}^{2}\right)$, residual variance $\left(\sigma_{R}^{2}\right)$, and heritability $\left(h^{2}\right)$

under spring calving for the lower $20 \%$ percentile herd milk production, and joint fifth under the bivariate reaction norm model under year-round calving for the lower $20 \%$ percentile herd milk production. Thus, increasing the complexity of the models did influence breeding values of bulls in different environments to some extent, but reranking was limited.

\section{DISCUSSION}

The main aim of this research was to investigate whether the combination of a multi-trait model and a reaction norm model would result in different insights compared with separate analyses. In general, results of the different models were similar, but some more insight was gained using the combined model. The main advantage of a combined reaction norm-multi-trait model is that when 2 environmental predictors are confounded their effects can be disentangled. In our case, average herd milk production is lower in the springcalving system. In the reaction norm analysis without information on the production system, this translated into higher residual variances at lower milk production. In the combined model, however, it can be seen that the decreasing trend in residual variances with increasing milk production is ambiguous, whereas the higher residual variance in spring calving is clear (Figure 1). Similarly, with the combined model, it can be seen that the higher additive variance in year-round calving is due to an increase in average herd milk production and not due to the production system.

Using the combined model may have practical consequences for animal breeders. The main consequence of $\mathrm{G} \times \mathrm{E}$ for animal breeders can be the need to set up different selection programs for different environments. A rough guideline is that genetic correlations above 0.80 have no importance in animal breeding (Robertson,
1959). Mulder et al. (2006) found that separate breeding programs are necessary when the genetic correlation is lower than 0.6 to 0.7 if bulls in a single breeding program are tested in both environments. In this study, genetic correlations between milk production levels were all close to unity regardless of the model used. The smallest correlation was found between the extreme milk yield levels in the year-round calving system, but it was still 0.98, and not significantly different from 1 .

Lower correlations were found between production systems. When differences in milk yield level were not taken into account, the genetic correlation between the 2 production systems was 0.91 (SE 0.06). When differences in milk production levels were taken into account, the genetic correlation between spring and year-round calving decreased to 0.82 to 0.84 . Unfortunately, standard errors for these last estimates could not be estimated because of nonconvergence of the model without fixing parameters. However, given the standard error of 0.06 for the correlation without milk yield being taken into account, it is unlikely that the estimates with milk yield would have differed significantly if the model had converged without fixing parameters. On the other hand, they might well have differed significantly from unity, in contrast to the estimate without milk yield being taken into account. Apart from the uncertainty of the estimates being significantly different or not in this particular case, the indication is that differences in milk production between herds may obscure lower genetic correlations between production levels.

Although correlations between milk production levels were at or close to unity, heritabilities and variance components differed between milk production levels. For additive genetic variances and heritabilities, differences between milk production levels were not large for the various models and, where available, approximate standard errors of the estimates overlapped and indi- 

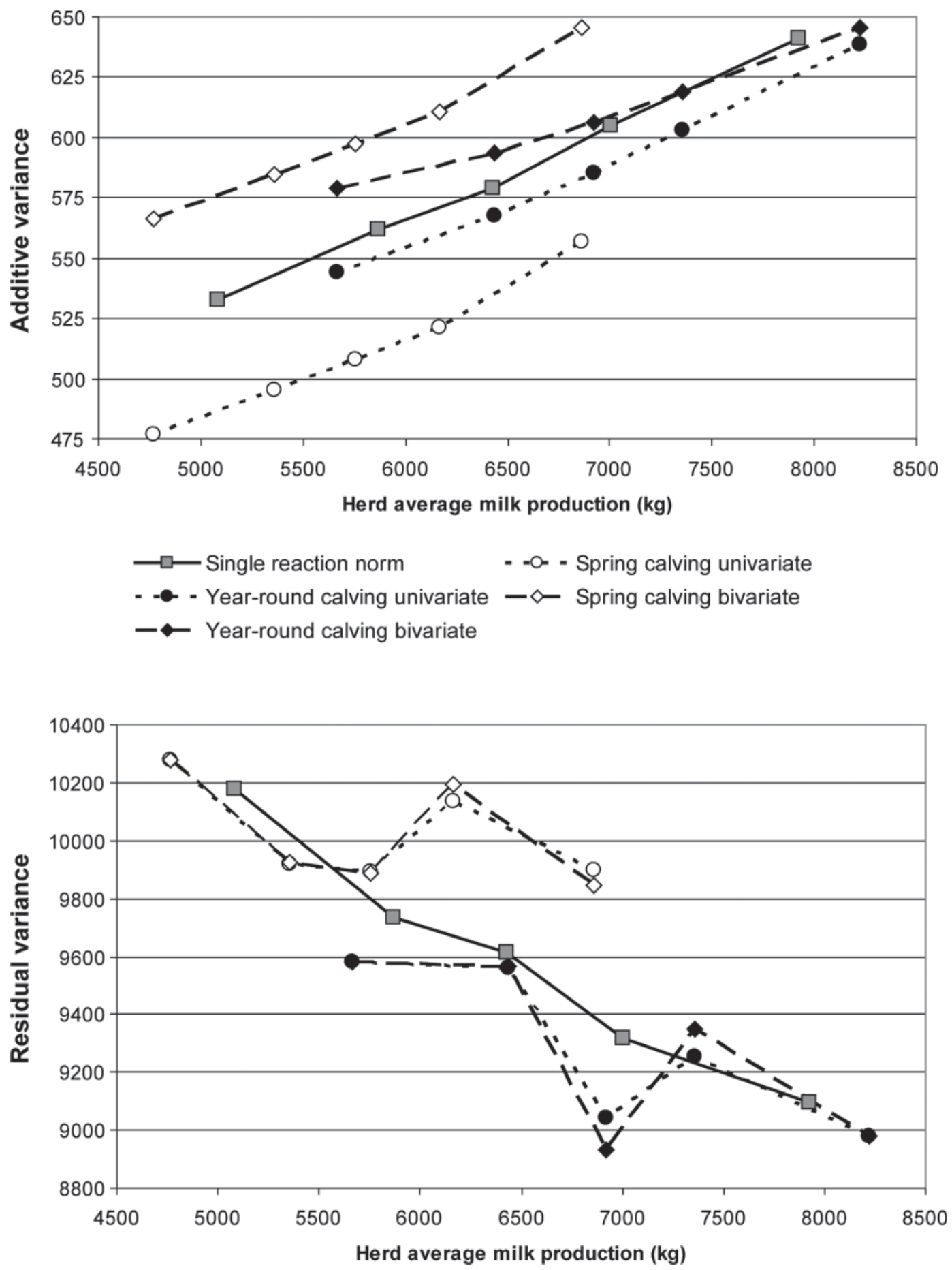

Figure 1. Additive genetic and residual variance components for SCS under various reaction norms. Standard errors for single reaction norm were, on average, 91 for additive variance and 150 for residual variance components.

cated no statistical significance. Differences were larger for the residual variance. In the reaction norm for yearround calving, estimates at both ends of the gradient differed by more than 4 standard errors, indicating a statistically significant difference. Unfortunately, stan- dard errors could not be estimated for the other reaction norm analyses. However, because differences and sample sizes were larger in the single reaction norm, it is safe to assume that these differences were real. On the other hand, in the spring-calving analysis, differ- 
Table 6. Genetic correlations across environments estimated with reaction norm models

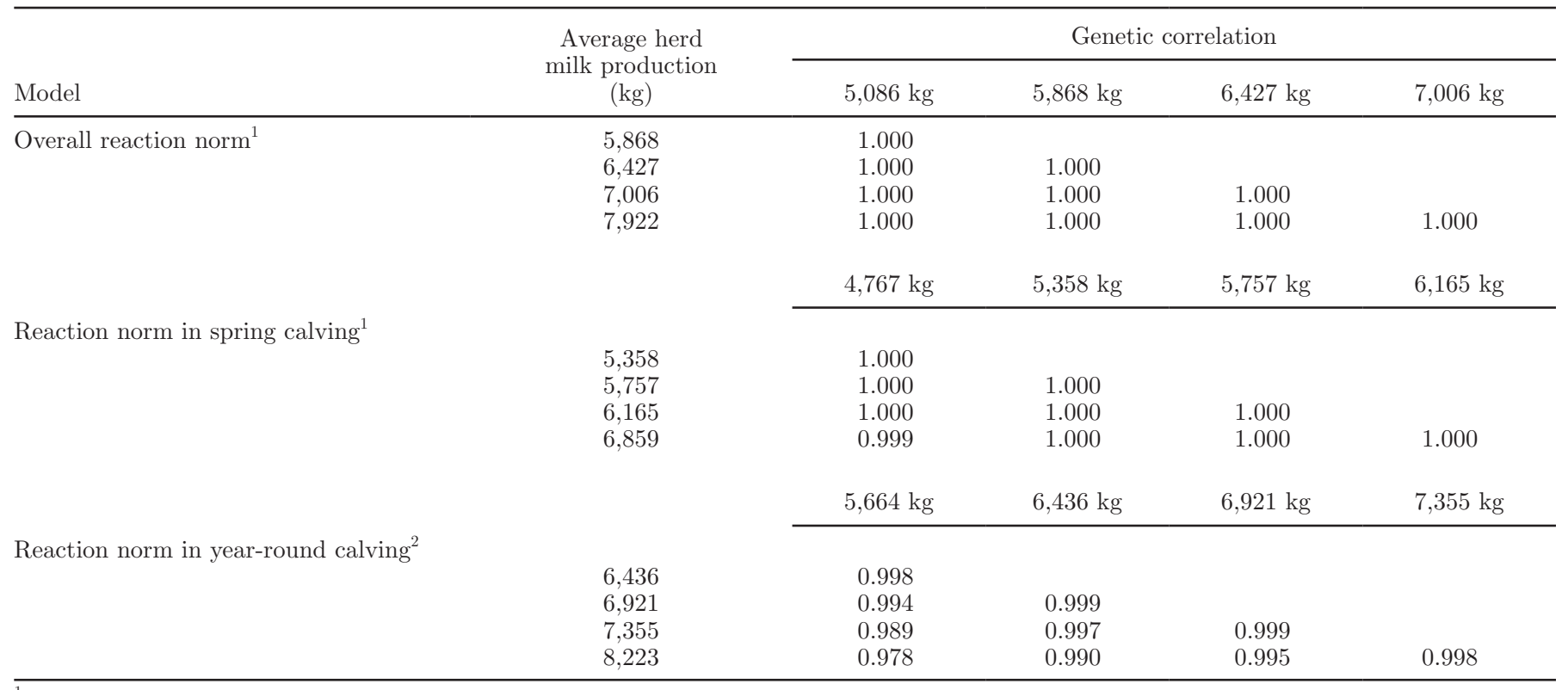

${ }^{1} \mathrm{SE}$ not estimated due to fixation of parameters.

${ }^{2}$ Average SE 0.028 .

ences and sample sizes were smaller and, consequently, the statistical significance of the result is doubtful. Despite this statistical uncertainty, however, it is likely that differences in the residual variance component observed for milk production in the bivariate reaction norm analysis are at least partly due to different production systems.
For the farmer, the main consequence of using a different model can be a change in the breeding value of a bull. Genetic correlations between environments lower than unity indicate reranking; that is, a bull with a high breeding value may be ranked lower in another environment. The breeding values of the most popular bulls indeed show some reranking (Table 8). Even with-

Table 7. Genetic correlations estimated with bivariate reaction norm model within and between discrete environments

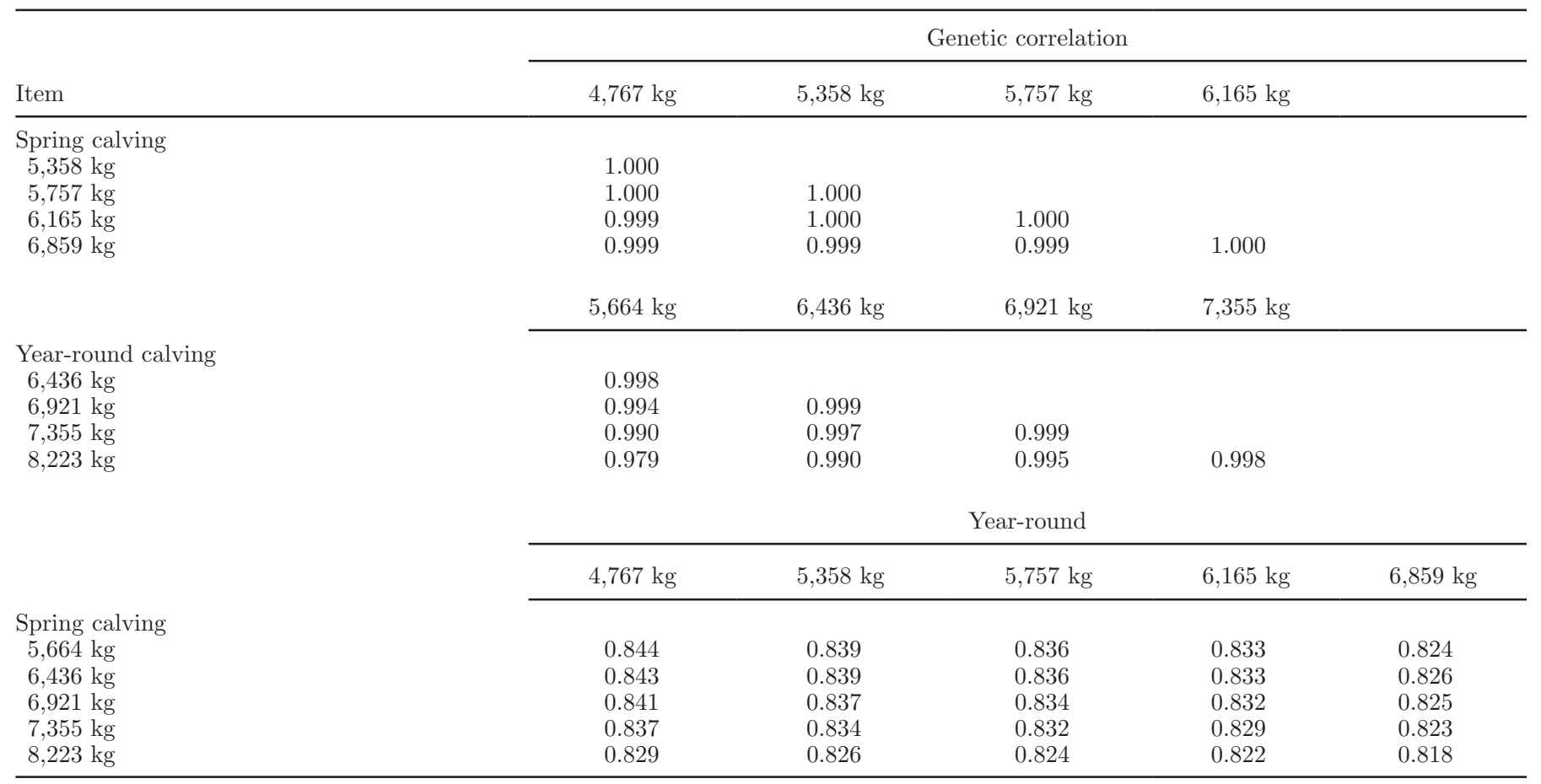


Table 8. Breeding values for SCS of the 12 sires with most daughters in the heifer data under different models (model numbers refer to Table 1)

\begin{tabular}{|c|c|c|c|c|c|c|c|c|c|}
\hline Bull & $\begin{array}{l}\text { Univariate } \\
\text { (1) }\end{array}$ & \multicolumn{3}{|c|}{ Spring calving } & \multicolumn{3}{|c|}{ Year-round calving } & & \\
\hline 1 & -14.5 & -14.2 & -14.1 & -13.9 & -15.3 & -14.3 & -14.6 & 4 & 23 \\
\hline 4 & -7.5 & -6.9 & -6.9 & -7.9 & -7.7 & -7.6 & -7.9 & 5 & 1 \\
\hline 5 & -5.9 & -5.7 & -5.5 & -5.6 & -6.2 & -5.0 & -5.1 & 7 & 52 \\
\hline 6 & -2.7 & -0.5 & 0.8 & -0.8 & -4.7 & -5.0 & -5.3 & 11 & 7 \\
\hline 7 & -0.9 & -1.4 & -1.2 & -0.4 & -0.8 & -1.2 & -1.2 & 18 & 4 \\
\hline 8 & 1.0 & 0.6 & -2.1 & 0.5 & 3.0 & 0.5 & 0.8 & 2 & 33 \\
\hline 9 & 3.3 & 2.5 & 2.6 & 1.8 & 3.5 & 3.3 & 3.3 & 26 & 3 \\
\hline 10 & 7.6 & 7.5 & 7.9 & 7.9 & 8.1 & 8.4 & 8.7 & 6 & 57 \\
\hline
\end{tabular}

${ }^{1}$ Popularity $=$ rank of number of heifer daughters per production environment.

${ }^{2}$ Bivariate reaction norms: left column $=$ lowest $20 \%$ percentile, right column $=$ highest $20 \%$ percentile average herd milk production.

out reranking, breeding values may change from one environment to the other so that, for example, the effect of using a high-ranking sire determined with one of the simpler models may be less than expected in some environments when analyzed with the combined model. In our case, the change in breeding values is limited; that is, the difference between the highest and lowest ranking bull is around 37 units and bulls change up to 3 units going from a model without environmental predictors to the combined model.

Genetic correlations between SCS in different environments reported in literature are generally close to unity. Genetic correlation for Dutch cows between environments based on milk production was 0.985 (Windig et al., 2006) and based on average SCS 0.93 (Calus et al., 2005), whereas in Italy a correlation of 0.96 was reported between a high and a low milk production system (Raffrenato et al., 2003). Nauta et al. (2006) reported a genetic correlation of 0.999 between SCS in organic and conventional dairy herds. For confined versus grazing herds in the United States, similar to the production systems investigated in our study, a genetic correlation of 0.92 was found (Kearney et al., 2004), very similar to the correlation of 0.91 estimated with the bivariate model in this study. The correlation of 0.82 estimated with the combined bivariate and reaction norm model is thus quite low compared with other estimates.

Convergence of reaction norm models was difficult for the spring calving and the combined model, because more than 1,000 iterations and fixing of some parameters were needed before the models converged. The cause was probably a low number of cows and number of daughters per sire in spring-calving herds. Many bulls were represented with fewer than 10 daughters in spring-calving production systems and with a multitude in year-round calving systems. In spring-calving systems, crossbreds and other breeds are used relatively more frequently, reducing the number of pure Holsteins per herd-year-season class. In general, applying a combined reaction-multi-trait model involves more (environmental) parameters and requires more data within and across herds than more conventional analyses.

\section{CONCLUSIONS}

New insights can be gained by combining reaction norm and multi-trait models. Effects of one environmental descriptor may be obscured by another, but can be disentangled in a combined analysis. Such models will be especially useful to analyze questions such as whether the effect of increasing production is more severe in, for example, conventional versus organic or low input production systems, or for disentangling geographic effects from farm-size effects (Konig et al., 2005).

\section{ACKNOWLEDGMENTS}

We are grateful to the Irish Cattle Breeding Federation (ICBF, Cork, Ireland) for providing the data set that was analyzed in this study. Erling Strandberg [Swedish Agricultural University (SLU), Uppsala, Sweden] and Brian Wickham (ICBF, Cork, Ireland) provided comments on earlier drafts. This work was carried out as part of the RobustMilk project that is 
financially supported by the European Commission under the Seventh Research Framework Programme, Grant Agreement KBBE-211708. The content of this paper is the sole responsibility of the authors, and it does not necessarily represent the views of the Commission or its services

\section{REFERENCES}

Aguilar, I., I. Misztal, and S. Tsuruta. 2009. Genetic components of heat stress for dairy cattle with multiple lactations. J. Dairy Sci. 92:5702-5711.

Calus, M. P. L., and R. F. Veerkamp. 2003. Estimation of environmental sensitivity of genetic merit for milk production traits using a random regression model. J. Dairy Sci. 86:3756-3764.

Calus, M. P. L., J. J. Windig, and R. F. Veerkamp. 2005. Associations among descriptors of herd management and phenotypic and genetic levels of health and fertility. J. Dairy Sci. 88:2178-2189.

Castillo-Juarez, H., P. A. Oltenacu, and E. G. Cienfuegos-Rivas. 2002. Genetic and phenotypic relationships among milk production and composition traits in primiparous Holstein cows in two different herd environments. Livest. Prod. Sci. 78:223-231.

de Haas, Y., W. Ouweltjes, J. ten Napel, J. J. Windig, and G. de Jong. 2008. Alternative somatic cell count traits as mastitis indicators for genetic selection. J. Dairy Sci. 91:2501-2511.

Evans, R. D., M. Wallace, D. J. Garrick, P. Dillon, D. P. Berry, and V. Olori. 2006. Effects of calving age, breed fraction and month of calving on calving interval and survival across parities in Irish spring-calving dairy cows. Livest. Sci. 100:216-230.

Falconer, D. S. 1952. The problem of environment and selection. Am. Nat. 86:293-298.

Fischer, T. M., A. R. Gilmour, and J. H. J. van der Werf. 2004. Computing approximate standard errors for genetic parameters derived from random regression models fitted by average information REML. Genet. Sel. Evol. 36:363-369.

Gilmour, A. R., B. R. Gogel, B. R. Cullis, and R. Thompson. 2006. ASREML User Guide Release 2.0. VSN International Ltd., Hemel Hempstead, UK.

Haile-Mariam, M., M. J. Carrick, and M. E. Goddard. 2008. Genotype by environment interaction for fertility, survival, and milk production traits in Australian dairy cattle. J. Dairy Sci. 91:4840-4853.

Hammami, H., B. Rekik, C. Bastin, H. Soyeurt, J. Bormann, J. Stoll, and N. Gengler. 2009. Environmental sensitivity for milk yield in Luxembourg and Tunisian Holsteins by herd management level. J. Dairy Sci. 92:4604-4612.
Kearney, J. F., M. M. Schutz, and P. J. Boettcher. 2004. Genotype $\times$ environment interaction for grazing vs. confinement. II. Health and reproduction traits. J. Dairy Sci. 87:510-516.

Kolmodin, R., E. Strandberg, P. Madsen, J. Jensen, and H. Jorjani. 2002. Genotype by environment interaction in Nordic dairy cattle studied using reaction norms. Acta Agric. Scand. Anim. Sci. 52:11-24.

König, S., G. Dietl, I. Raeder, and H. H. Swalve. 2005. Genetic relationships for dairy performance between large-scale and smallscale farm conditions. J. Dairy Sci. 88:4087-4096.

Mulder, H. A., R. F. Veerkamp, B. J. Ducro, J. A. M. van Arendonk, and P. Bijma. 2006. Optimization of dairy cattle breeding programs for different environments with genotype by environment interaction. J. Dairy Sci. 89:1740-1752.

Nauta, W. J., R. F. Veerkamp, E. W. Brascamp, and H. Bovenhuis. 2006. Genotype by environment interaction for milk production traits between organic and conventional dairy cattle production in the Netherlands. J. Dairy Sci. 89:2729-2737.

Raffrenato, E., R. W. Blake, P. A. Oltenacu, J. Carvalheira, and G. Licitra. 2003. Genotype by environment interaction for yield and somatic cell score with alternative environmental definitions. J. Dairy Sci. 86:2470-2479.

Ravagnolo, O., and I. Misztal. 2002. Effect of heat stress on nonreturn rate in Holstein cows: Genetic analyses. J. Dairy Sci. 85:30923100 .

Robertson, A. 1959. The sampling variance of the genetic correlation coefficient. Biometrics 15:469-485.

Roxstrom, A., E. Strandberg, B. Berglund, U. Emanuelson, and J. Philipsson. 2001. Genetic and environmental correlations among female fertility traits and milk production in different parities of Swedish red and white dairy cattle. Acta Agric. Scand. Anim. Sci. 51:7-14.

Tsuruta, S., I. Misztal, C. Huang, and T. J. Lawlor. 2009. Bivariate analysis of conception rates and test-day milk yields in Holsteins using a threshold-linear model with random regressions. J. Dairy Sci. 92:2922-2930.

Van Tienderen, P. H., and H. P. Koelewijn. 1994. Selection on reaction norms, genetic correlations and constraints. Genet. Res. $64: 115-125$.

Windig, J. J., M. P. L. Calus, B. Beerda, and R. F. Veerkamp. 2006. Genetic correlations between milk production and health and fertility depending on herd environment. J. Dairy Sci. 89:1765-1775.

Windig, J. J., M. P. L. Calus, and R. F. Veerkamp. 2005. Influence of herd environment on health and fertility and their relationship with milk production. J. Dairy Sci. 88:335-347. 